\title{
Screening of JAK-STAT modulators from the antiviral plants of Indian traditional system of medicine with the potential to inhibit 2019 novel coronavirus using network pharmacology
}

\author{
Pukar Khanal ${ }^{1}$ (1) $\cdot$ Taaza Duyu $^{1} \cdot$ B. M. Patil ${ }^{1} \cdot$ Yadu Nandan Dey ${ }^{2} \cdot$ Ismail Pasha $^{3} \cdot$ Rohini S. Kavalapure $^{4}$. \\ Sharad Chand ${ }^{5} \cdot$ Shailendra Gurav ${ }^{6}$
}

Received: 13 November 2020 / Accepted: 18 January 2021 / Published online: 8 February 2021

(c) King Abdulaziz City for Science and Technology 2021

\begin{abstract}
The majority of the bioactives under investigation were predicted to target TNF receptor-associated factor 5 in the Janus kinase/signal transducers and activators of the transcription pathway. Similarly, druglikeness prediction identified vitexilactone to possess the highest druglikeness score, i.e., 0.88. Furthermore, proteins targeted in the Janus kinase/signal transducers and activators of transcription pathway were also predicted to regulate multiple pathways, i.e., ErbB, AGE-RAGE, NF-kappa $\mathrm{B}$, Measles, insulin, mTOR, chemokine, Ras, and pathways associated with infectious and non-infectious pathogenesis, where the immune system is compromised. Similarly, the docking study identified sesaminol 2-O- $\beta$-D-gentiobioside to possess the highest binding affinity with $3 \mathrm{CL}^{\mathrm{pro}}, \mathrm{PL}^{\mathrm{pro}}$, and spike proteins. Furthermore, phylogeny comparison identified the common protein domains with other stains of microbes like murine hepatitis virus strain A59, avian infectious bronchitis virus, and porcine epidemic diarrhea virus CV777.
\end{abstract}

Keywords $3 \mathrm{CL}^{\mathrm{pro}} \cdot$ Anti-viral $\cdot$ Coronavirus $\cdot$ COVID-19 $\cdot$ JAK-STAT pathway $\cdot$ PL $^{\text {pro }} \cdot$ Spike protein

\section{Introduction}

Coronavirus disease 2019 (COVID-19) has emerged as a public health concern in terms of mortality and economic loss. Originating from China, COVID-19 drastically spread throughout the world quickly and affected more than 50 different countries (Zhang et al. 2020). World Health Organization declared COVID-19 as "Pandemic" and has suggested

Ismail Pasha, Rohini S. Kavalapure, Sharad Chand and Shailendra Gurav authors possess equal contribution in the manuscript.

Pukar Khanal

pukarkhanal58@gmail.com

$\triangle$ B. M. Patil

drbmpatil@klepharm.edu; bmpatil59@hotmail.com

Yadu Nandan Dey

yadunandan132@gmail.com

1 Department of Pharmacology and Toxicology, KLE College of Pharmacy Belagavi, KLE Academy of Higher Education and Research (KAHER), Belagavi 590010, India

2 School of Pharmaceutical Technology, Adamas University, Kolkata, India preventive approaches like social isolation and intensive care of patients (WHO 2020). Recent in-silico and network pharmacology studies have reported repurposing of existing drugs and the alleged role of natural lead in the treatment of COVID-19 (Sinha et al. 2020a,b; Chikhale et al. 2020a,b,c; Patil et al. 2020; Khanal et al. 2020a,b, 2021a,b). The earlier reports indicated the Janus kinase/signal transducer and activator of transcription (JAK-STAT) pathway's deregulation during host invasion of coronavirus by affecting the type I IFNs synthesis (Luo et al 2020). But, the stimulation of

3 Department of Pharmacology, Orotta College of Medicine and Health Sciences, Asmara University, Asmara, Eritrea

4 Department of Pharmaceutical Chemistry, KLE College of Pharmacy Belagavi, KLE Academy of Higher Education and Research (KAHER), Belagavi 590010, India

5 Department of Pharmacy Practice, NGSM Institute of Pharmaceutical Sciences, NITTE (Deemed To Be University), Paneer, Deralakatte, Mangaluru, Karnataka 575018, India

6 Department of Pharmacognosy, Goa College of Pharmacy, Goa University, Panaji, Goa 403 001, India 
IFN by host cells helps in immune modulation and prevent viruses' spreading (Li et al. 2020). Furthermore, comorbid patients with compromised immunity are more prone and carry a higher risk for COVID-19 infection (Khanal et al 2020a,b). The manipulation of the JAK-STAT pathway due to its close association with the immune system can manage the COVID-19 infection (Villarino et al. 2017; Satarker et al. 2020). Hence, the JAK-STAT pathway's multiple protein expression modulations would regulate IFN-associated genes' production (Satarker et al. 2020) to minimize viral infection.

Furthermore, coronavirus is composed of multiple proteins such as $3 \mathrm{C}$-like protease $\left(3 \mathrm{CL}^{\mathrm{pro}}\right)$, papain-like protease $\left(\mathrm{PL}^{\mathrm{pro}}\right)$, and spike protein that play an essential role in host entry and replication (Bhoj and Chen 2009; Lindner et al. 2005; Patil et al. 2020). Furthermore, 3CL ${ }^{\text {pro }}$ alters the ubiquitin system and also modifies the functional protein by incorporating the viral polypeptides (Bhoj and Chen 2009), whereas PL ${ }^{\text {ro }}$ is reported to process pp $1 \mathrm{a}$ and pplab into the replicase proteins and plays a crucial task in the viral life cycle (Lindner et al. 2005). Likewise, spike protein utilizes angiotensin-converting enzyme 2 as a receptor to enter inside the cell (Kuhn et al. 2004; Patil et al. 2020). Hence, these three proteins of coronavirus could be the targets of interest for investigations to manage COVID-19.

Indian traditional system of medicines described many anti-viral plants that are effective in controlling viral infection. Given the scarcity of treatment to combat COVID-19, the present study focused on identifying JAK-STAT pathway regulators by network pharmacology and predicting the probable lead hits to act over $3 \mathrm{CL}^{\text {pro }}$, $\mathrm{PL}^{\text {pro }}$, and spike protein using in-silico molecular docking. The complete flow line for the present study is depicted in Fig. 1.

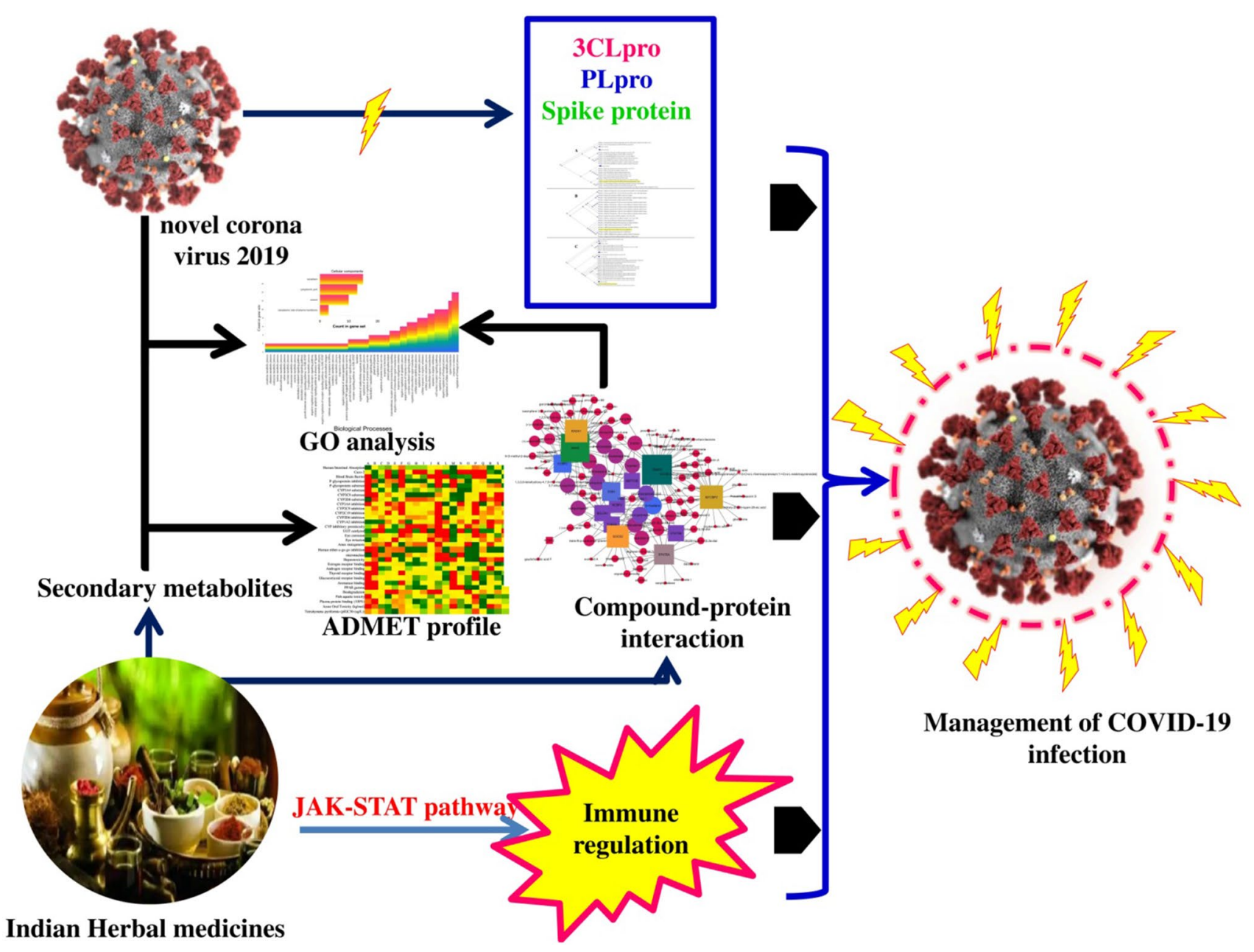

Fig. 1 Flowline of the study to identify the JAK-STAT modulators and $3 \mathrm{CL}^{\text {pro }}, \mathrm{PL}^{\text {pro }}$, and spike protein inhibitors from Indian medicinal plants 


\section{Methodology}

\section{Compounds mining and their gene expression study}

The traditional anti-viral plants were identified from the open-source database and published literature. The list of each phytoconstituent was retrieved using the Chemical Entities of Biological Interest (ChEBI) database (https:// www.ebi.ac.uk/chebi). Their simplified molecular input line entry system (SMILES) was queried in DIGEP-Pred (Lagunin et al. 2013) to identify the probable expression of genes based on mRNA expression at the pharmacological activity $(\mathrm{Pa})>0.5$. A complete datasheet comprising the list of plants, their phytoconstituents, and their expression profile was constructed.

\section{Identification of proteins involved in the JAK-STAT pathway}

We identified the proteins involved in the JAK-STAT signaling pathway from the Kyoto Encyclopedia of Genes and Genomes (KEGG) pathway database (pathway ID: hsa04630) (https://www.genome.jp/kegg/pathway.html).
Furthermore, "Pivot Table" was used to determine the phytoconstituents and the highest count of proteins involved in the JAK-STAT pathway. Multiple keywords "STAM, JAK, TC-PTP, SHP1, STAT, SHP2\GRB, PI3K, AKT, SOS, IRF9, Ras, Raf, mTOR, PIAS, SLIM, CBPP300, CIS, Bcl-2, BclXL, c-Myc, p21, AOX, GFAP, SOCS, MCL1, PIM1, and CycD" were used to identify the modulators of the JAKSTAT pathway concerning KEGG pathway; hsa04630.

\section{Enrichment analysis, network construction, and hit identification}

We performed an enrichment analysis of the JAK-STAT pathway's expressed targets by querying a list of modulated proteins using a search tool for the retrieval of interacting genes/proteins (Szklarczyk et al. 2019) and identified biological processes, cellular components, and regulated pathways concerning KEGG. The network interaction of phytoconstituents and modulated proteins from JAK-STAT pathway was constructed using Cytoscape (Shannon et al. 2003) version 3.7.1. The constructed network was analyzed based on edge count by treating the network as directed and setting the node size as "low values to small sizes" and color

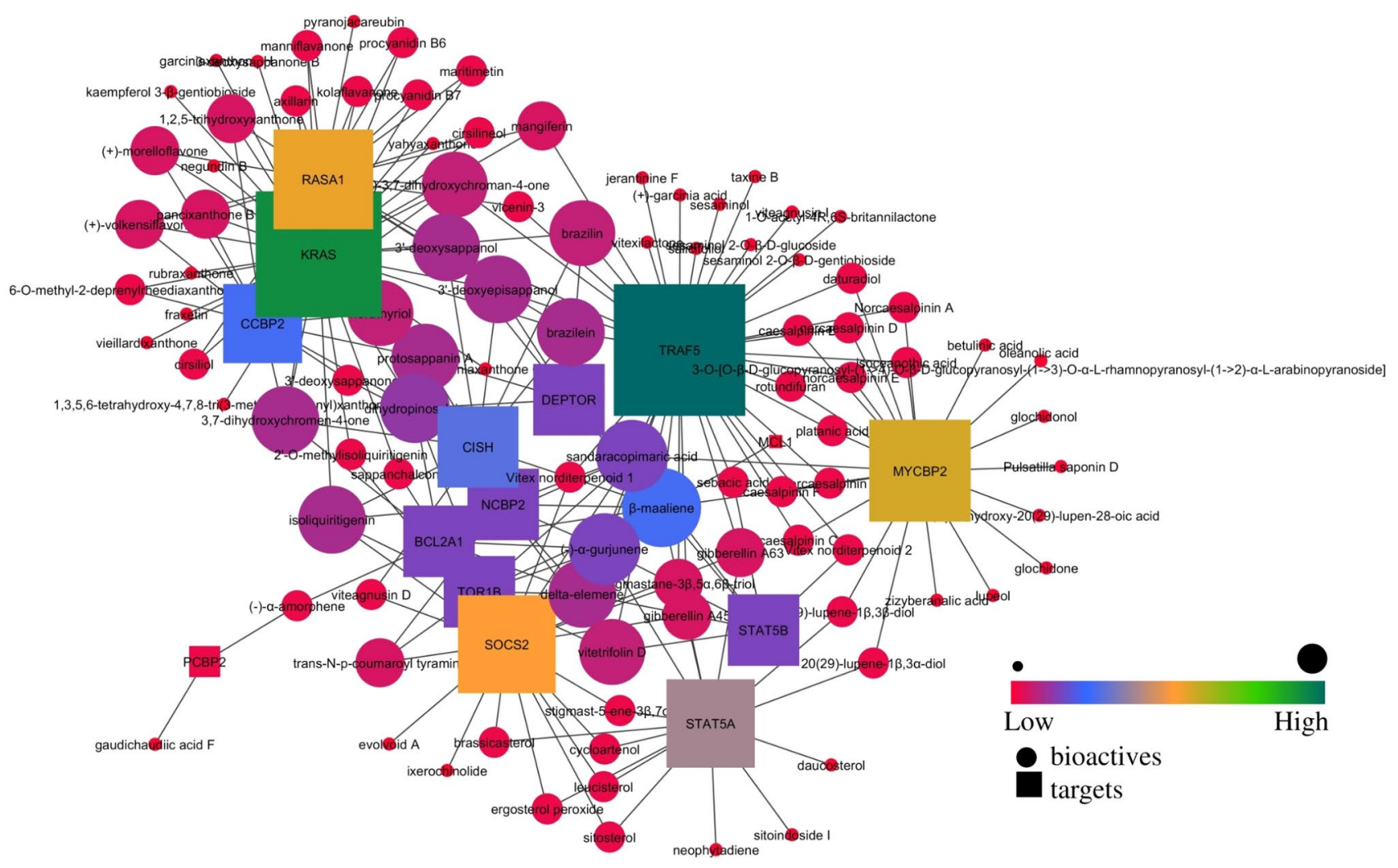

Fig. 2 Interaction of phytoconstituents with proteins involved in the JAK-STAT pathway

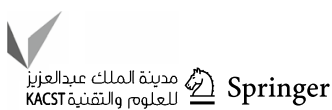




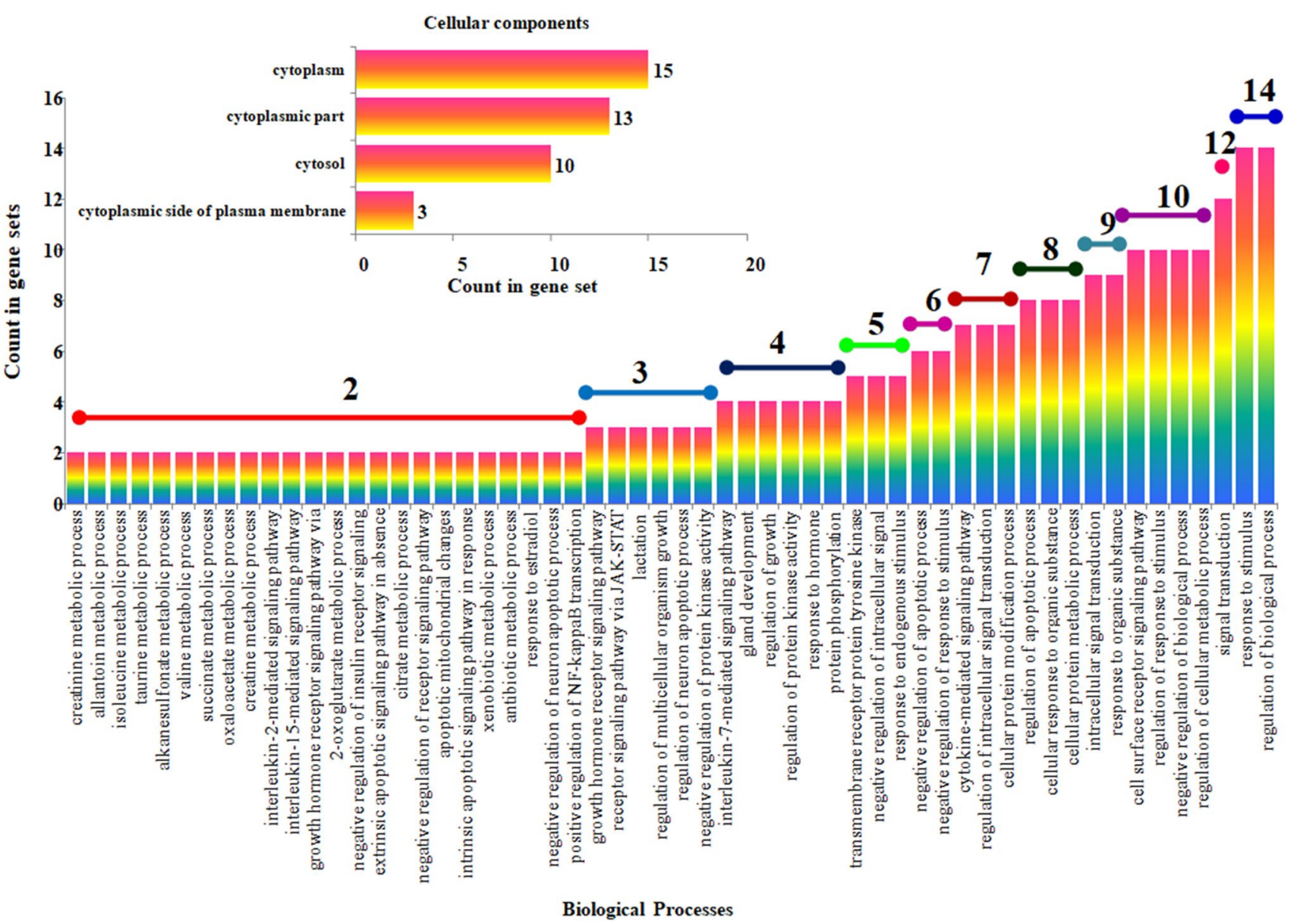

Fig. 3 Gene ontology analysis of regulated proteins from the JAK-STAT pathway

as "low values to bright colors". Then the protein targeted by the highest number of phytoconstituents was further chosen as a target for docking.

\section{Druglikeness and absorption, distribution, metabolism, excretion, and toxicity (ADMET) profile of lead hits}

We predicted the probable oral bioavailability and a druglikeness score of hit phytoconstituents using Lipinski's rule of five (Lipinski 2004). According to Lipinski's rule of five, only two violations may be accepted for human intestinal absorptivity. Similarly, the ADMET profile of lead hits was calculated using admetSAR2.0 (Yang et al. 2019). Using admetSAR2.0, multiple parameters for ADMET profile like human intestinal absorption, Caco-2, and blood-brain barrier permeability, inhibition/substrate of P-glycoprotein, CYP3A4, CYP2C9, CYP2D6, CYP3A4, CYP2C19, CYP1A2, and toxicity effects like eye corrosion/irritation, ames mutagenesis, human either-a-go-go inhibition, micronuclear, hepatotoxicity, fish aquatic toxicity, acute oral toxicity, and Tetrahymena pyriformis and binding affinity for multiple proteins like estrogen, androgen, thyroid, glucocorticoid, and aromatase receptor, PPAR- $\gamma$ and plasma protein binding was predicted.

\section{In silico molecular docking}

The crystallographic protein of Tumor necrosis factor receptor-associated factor 5 (TRAF5) for humans with complete amino acid residues was not found in Research Collaboratory for Structural Bioinformatics (RCSB) protein databank (https://www.rcsb.org/). Hence, homology modeling was performed for TRAF5 using the FASTA sequence of AAH29600.1 as a query sequence against TRAF5 from $M u s$ musculus as a template (PDB: 4GJH) using SWISS-MODEL (Schwede et al. 2003). Pre-complexed hetero-molecules from the retrieved target were removed using Discovery studio (Dassault Systèmes BIOVIA) 2019 and saved in.pdb format. The corresponding 3D structure of each ligand against TRAF5 was retrieved from the PubChem database (https:// pubchem.ncbi.nlm.nih.gov/) in.sdf format, converted into. 
Table 1 Enrichment analysis of modulated proteins from JAKSTAT pathway

\begin{tabular}{|c|c|c|c|c|}
\hline $\begin{array}{l}\text { Pathway } \\
\text { ID }\end{array}$ & Pathway description & $\begin{array}{l}\text { Observed } \\
\text { gene count }\end{array}$ & Matching proteins in network & $\begin{array}{l}\text { False discovery } \\
\text { rate }\end{array}$ \\
\hline hsa04917 & Prolactin signaling pathway & 5 & $\begin{array}{l}\text { CISH, KRAS, SOCS2, STAT5A, } \\
\text { STAT5B }\end{array}$ & $1.76 \mathrm{E}-07$ \\
\hline hsa04630 & $\begin{array}{ll}\text { Jak-STAT } & \text { signaling } \\
\text { pathway } & \\
\end{array}$ & 5 & $\begin{array}{l}\text { CISH, MCL1, SOCS2, STAT5A, } \\
\text { STAT5B }\end{array}$ & $5.05 \mathrm{E}-06$ \\
\hline hsa05221 & Acute myeloid leukemia & 4 & $\begin{array}{lll}\text { BCL2A1, } & \text { KRAS, } & \text { STAT5A, } \\
\text { STAT5B } & & \\
\end{array}$ & $5.95 \mathrm{E}-06$ \\
\hline hsa05203 & Viral carcinogenesis & 4 & $\begin{array}{lll}\text { KRAS, } & \text { STAT5A, } & \text { STAT5B, } \\
\text { TRAF5 } & & \\
\end{array}$ & 0.00023 \\
\hline hsa05223 & Non-small cell lung cancer & 3 & KRAS, STAT5A, STAT5B & 0.00033 \\
\hline hsa05220 & Chronic myeloid leukemia & 3 & KRAS, STAT5A, STAT5B & 0.00042 \\
\hline hsa04012 & ErbB signaling pathway & 3 & KRAS, STAT5A, STAT5B & 0.00046 \\
\hline hsa04933 & $\begin{array}{lr}\text { AGE-RAGE } & \text { signaling } \\
\text { pathway in diabetic } \\
\text { complications }\end{array}$ & 3 & KRAS, STAT5A, STAT5B & 0.00065 \\
\hline hsa04210 & Apoptosis & 3 & BCL2A1, KRAS, MCL1 & 0.0015 \\
\hline hsa05161 & Hepatitis B & 3 & KRAS, STAT5A, STAT5B & 0.0015 \\
\hline hsa04217 & Necroptosis & 3 & STAT5A, STAT5B, TRAF5 & 0.0018 \\
\hline hsa05200 & Pathways in cancer & 4 & $\begin{array}{lll}\text { KRAS, } & \text { STAT5A, } & \text { STAT5B, } \\
\text { TRAF5 } & & \\
\end{array}$ & 0.004 \\
\hline hsa05166 & HTLV-I infection & 3 & KRAS, STAT5A, STAT5B & 0.006 \\
\hline hsa04658 & $\begin{array}{lcc}\begin{array}{l}\text { Th1 and } \\
\text { differentiation }\end{array} & \text { Th2 } & \text { cell } \\
\end{array}$ & 2 & STAT5A, STAT5B & 0.0136 \\
\hline hsa04064 & $\begin{array}{llr}\begin{array}{l}\text { NF-kappa } \\
\text { pathway }\end{array} & \text { B signaling } \\
\end{array}$ & 2 & BCL2A1, TRAF5 & 0.0141 \\
\hline hsa04659 & Th17 cell differentiation & 2 & STAT5A, STAT5B & 0.0158 \\
\hline hsa04140 & Autophagy - animal & 2 & DEPTOR, KRAS & 0.022 \\
\hline hsa04910 & Insulin signaling pathway & 2 & KRAS, SOCS2 & 0.0234 \\
\hline hsa05162 & Measles & 2 & STAT5A, STAT5B & 0.0234 \\
\hline hsa04150 & mTOR signaling pathway & 2 & DEPTOR, KRAS & 0.0258 \\
\hline hsa05206 & MicroRNAs in cancer & 2 & KRAS, MCL1 & 0.0258 \\
\hline hsa04360 & Axon guidance & 2 & KRAS, RASA1 & 0.0316 \\
\hline hsa04062 & $\begin{array}{ll}\begin{array}{l}\text { Chemokine } \\
\text { pathway }\end{array} & \text { signaling } \\
\end{array}$ & 2 & KRAS, STAT5B & 0.0329 \\
\hline hsa04014 & Ras signaling pathway & 2 & KRAS, RASA1 & 0.0489 \\
\hline
\end{tabular}

Low

pdb format using Discovery studio 2019; drawn in Marvin sketch (https://chemaxon.com/products/marvin) and converted into 3D.pdb format if not available. Each molecule's energy was minimized using mmff94 forcefield (Halgren 1996) and converted into.pdbqt format. Autodock4 (Morris et al. 2009) was used for docking the identified ligands with TRAF5 to get ten different ligand poses. The minimum binding energy scored pose was chosen to visualize the ligand-protein interaction using Discovery studio. Furthermore, we assessed the binding affinity of lead hits with 3CL ${ }^{\text {pro }}$ (PDB: 6LU7), PL ${ }^{\text {pro }}$ (PDB: 4M0W), and spike proteins (homology modeled target, accession number:
AVP78042.1 as query sequence and PDB: 6VSB as a template using SWISS-MODEL) as previously explained.

\section{Phylogeny comparison of $3 \mathrm{CL}^{\text {pro }}, \mathrm{PL}^{\text {pro }}$, and spike protein}

The FASTA sequence of 3CL pro (accession:1P9U_A, GI: 31,616,013), PL ${ }^{\text {pro }}$ (accession: 4WUR_A, GI: 726,969,143), and spike protein (accession: AVP78042.1 GI: 1,369,125,431) were retrieved from NCBI-protein and compared with the RCSB protein bank database to identify the possible homologous proteins using BlastP (Altschul et al. 1997). 
Table 2 Druglikeness of phytoconstituents targeting TNF receptor-associated factor 5

\begin{tabular}{|c|c|c|c|c|c|c|c|}
\hline Phytoconstituents & $\begin{array}{l}\text { Molecular } \\
\text { formula }\end{array}$ & $\begin{array}{l}\text { Molecular } \\
\text { weight }\end{array}$ & NHBA & NHBD & MolLogP & $\begin{array}{l}\text { MolLogS } \\
(\log (\text { moles} / L))\end{array}$ & DLS \\
\hline$(-)$ - $\alpha$-gurjunene & $\mathrm{C}_{15} \mathrm{H}_{24}$ & 204.19 & 0 & 0 & 5.03 & -4.81 & -1.18 \\
\hline$(+)$-garcinia acid & $\mathrm{C}_{6} \mathrm{H}_{6} \mathrm{O}_{7}$ & 190.01 & 7 & 3 & -2.25 & -0.18 & -0.92 \\
\hline (S)-3,7-dihydroxychroman-4-one & $\mathrm{C}_{9} \mathrm{H}_{8} \mathrm{O}_{4}$ & 180.04 & 4 & 2 & 0.28 & -2.07 & 0.24 \\
\hline 1-O-acetyl-4R,6S-britannilactone & $\mathrm{C}_{17} \mathrm{H}_{24} \mathrm{O}_{5}$ & 308.16 & 5 & 1 & 1.88 & -1.51 & 0.08 \\
\hline 3'-deoxyepisappanol & $\mathrm{C}_{16} \mathrm{H}_{16} \mathrm{O}_{5}$ & 288.10 & 5 & 4 & 1.50 & -1.38 & -0.09 \\
\hline 3'-deoxysappanol & $\mathrm{C}_{16} \mathrm{H}_{16} \mathrm{O}_{5}$ & 288.10 & 5 & 4 & 1.50 & -1.38 & -0.09 \\
\hline$\beta$-maaliene & $\mathrm{C}_{15} \mathrm{H}_{24}$ & 204.19 & 0 & $\overline{0}$ & 4.95 & -4.70 & -0.51 \\
\hline Brazilein & $\mathrm{C}_{16} \mathrm{H}_{12} \mathrm{O}_{5}$ & 284.07 & 5 & 3 & 1.01 & -2.37 & -0.56 \\
\hline Brazilin & $\mathrm{C}_{16} \mathrm{H}_{14} \mathrm{O}_{5}$ & 286.08 & 5 & 4 & 1.68 & -1.58 & -0.49 \\
\hline Caesalpinin $\mathrm{C}$ & $\mathrm{C}_{24} \mathrm{H}_{32} \mathrm{O}_{6}$ & 416.22 & 6 & 1 & 3.46 & -3.32 & -0.16 \\
\hline Caesalpinin D & $\mathrm{C}_{24} \mathrm{H}_{30} \mathrm{O}_{8}$ & 446.19 & 8 & 1 & 2.34 & -2.40 & -0.48 \\
\hline Caesalpinin F & $\mathrm{C}_{23} \mathrm{H}_{30} \mathrm{O}_{7}$ & 418.20 & 7 & 1 & 2.59 & -2.73 & 0.33 \\
\hline Daturadiol & $\mathrm{C}_{30} \mathrm{H}_{50} \mathrm{O}_{2}$ & 442.38 & 2 & 2 & 6.78 & -5.91 & -0.04 \\
\hline$\delta$-elemene & $\mathrm{C}_{15} \mathrm{H}_{24}$ & 204.19 & 0 & 0 & 5.51 & -5.41 & -1.19 \\
\hline Isoceanothic acid & $\mathrm{C}_{30} \mathrm{H}_{46} \mathrm{O}_{5}$ & 486.33 & 5 & 3 & 5.36 & -5.13 & 0.19 \\
\hline Jerantinine $\mathrm{F}$ & $\mathrm{C}_{22} \mathrm{H}_{26} \mathrm{~N}_{2} \mathrm{O}_{5}$ & 398.18 & 6 & 2 & 2.33 & -2.80 & 0.31 \\
\hline Mangiferin & $\mathrm{C}_{19} \mathrm{H}_{18} \mathrm{O}_{11}$ & 422.08 & 11 & 8 & -0.13 & -1.49 & 0.25 \\
\hline Norcaesalpinin A & $\mathrm{C}_{23} \mathrm{H}_{30} \mathrm{O}_{7}$ & 418.20 & 7 & 1 & 2.38 & -2.52 & 0.26 \\
\hline Norcaesalpinin B & $\mathrm{C}_{23} \mathrm{H}_{30} \mathrm{O}_{7}$ & 418.20 & 7 & 1 & 2.55 & -2.53 & 0.20 \\
\hline Norcaesalpinin D & $\mathrm{C}_{25} \mathrm{H}_{32} \mathrm{O}_{9}$ & 476.20 & 9 & 1 & 2.15 & -2.37 & 0.17 \\
\hline Norcaesalpinin E & $\mathrm{C}_{21} \mathrm{H}_{28} \mathrm{O}_{6}$ & 376.19 & 6 & 2 & 1.89 & -2.23 & 0.55 \\
\hline Platanic acid & $\mathrm{C}_{29} \mathrm{H}_{46} \mathrm{O}_{4}$ & 458.34 & 4 & 2 & 4.82 & -4.38 & 0.58 \\
\hline Rotundifuran & $\mathrm{C}_{22} \mathrm{H}_{34} \mathrm{O}_{4}$ & 362.25 & 4 & 1 & 4.67 & -4.45 & 0.17 \\
\hline Salicifoliol & $\mathrm{C}_{13} \mathrm{H}_{14} \mathrm{O}_{5}$ & 250.08 & 5 & 1 & 0.62 & -1.45 & 0.06 \\
\hline Sandaracopimaric acid & $\mathrm{C}_{20} \mathrm{H}_{30} \mathrm{O}_{2}$ & 302.22 & 2 & 1 & 4.48 & -4.40 & -0.55 \\
\hline Sebacic acid & $\mathrm{C}_{10} \mathrm{H}_{18} \mathrm{O}_{4}$ & 202.12 & 4 & 2 & 1.37 & -1.31 & -0.01 \\
\hline Sesaminol & $\mathrm{C}_{20} \mathrm{H}_{18} \mathrm{O}_{7}$ & 370.11 & 7 & 1 & 3.02 & -2.71 & -0.55 \\
\hline Sesaminol 2-O- $\beta$-D-gentiobioside & $\mathrm{C}_{32} \mathrm{H}_{38} \mathrm{O}_{17}$ & 694.21 & 17 & 7 & -0.88 & -1.19 & -0.23 \\
\hline Sesaminol 2-O- $\beta$-D-glucoside & $\mathrm{C}_{26} \mathrm{H}_{28} \mathrm{O}_{12}$ & 532.16 & 12 & 4 & 0.99 & -1.30 & -0.26 \\
\hline Stigmastane- $3 \beta, 5 \alpha, 6 \beta$-triol & $\mathrm{C}_{29} \mathrm{H}_{52} \mathrm{O}_{3}$ & 448.39 & 3 & 3 & 6.52 & -6.05 & 0.56 \\
\hline Taxine B & $\mathrm{C}_{33} \mathrm{H}_{45} \mathrm{NO}_{8}$ & 583.31 & 9 & 3 & 2.24 & -2.61 & 0.82 \\
\hline Vicenin-3 & $\mathrm{C}_{26} \mathrm{H}_{28} \mathrm{O}_{14}$ & 564.15 & 14 & 10 & -0.52 & -1.43 & 0.32 \\
\hline Viteagnusin I & $\mathrm{C}_{22} \mathrm{H}_{34} \mathrm{O}_{6}$ & 394.24 & 6 & 2 & 3.26 & -3.55 & 0.71 \\
\hline Vitetrifolin D & $\mathrm{C}_{24} \mathrm{H}_{38} \mathrm{O} 5$ & 406.27 & 5 & 1 & 4.83 & -4.43 & 0.82 \\
\hline Vitex norditerpenoid 1 & $\mathrm{C}_{19} \mathrm{H}_{30} \mathrm{O}_{2}$ & 290.22 & 2 & 0 & 3.93 & -3.98 & -0.57 \\
\hline Vitex norditerpenoid 2 & $\mathrm{C}_{21} \mathrm{H}_{32} \mathrm{O}_{4}$ & 348.23 & 4 & 0 & 3.85 & -3.75 & 0.30 \\
\hline Vitexilactone & $\mathrm{C}_{22} \mathrm{H}_{34} \mathrm{O}_{5}$ & 378.24 & 5 & 1 & 3.55 & -3.86 & 0.88 \\
\hline Gibberellin A45 & $\mathrm{C}_{19} \mathrm{H}_{24} \mathrm{O}_{5}$ & 332.16 & 5 & 2 & 1.23 & -1.40 & -0.60 \\
\hline Gibberellin A63 & $\mathrm{C}_{19} \mathrm{H}_{24} \mathrm{O}_{6}$ & 348.16 & 6 & 3 & 0.34 & -0.78 & -0.59 \\
\hline
\end{tabular}




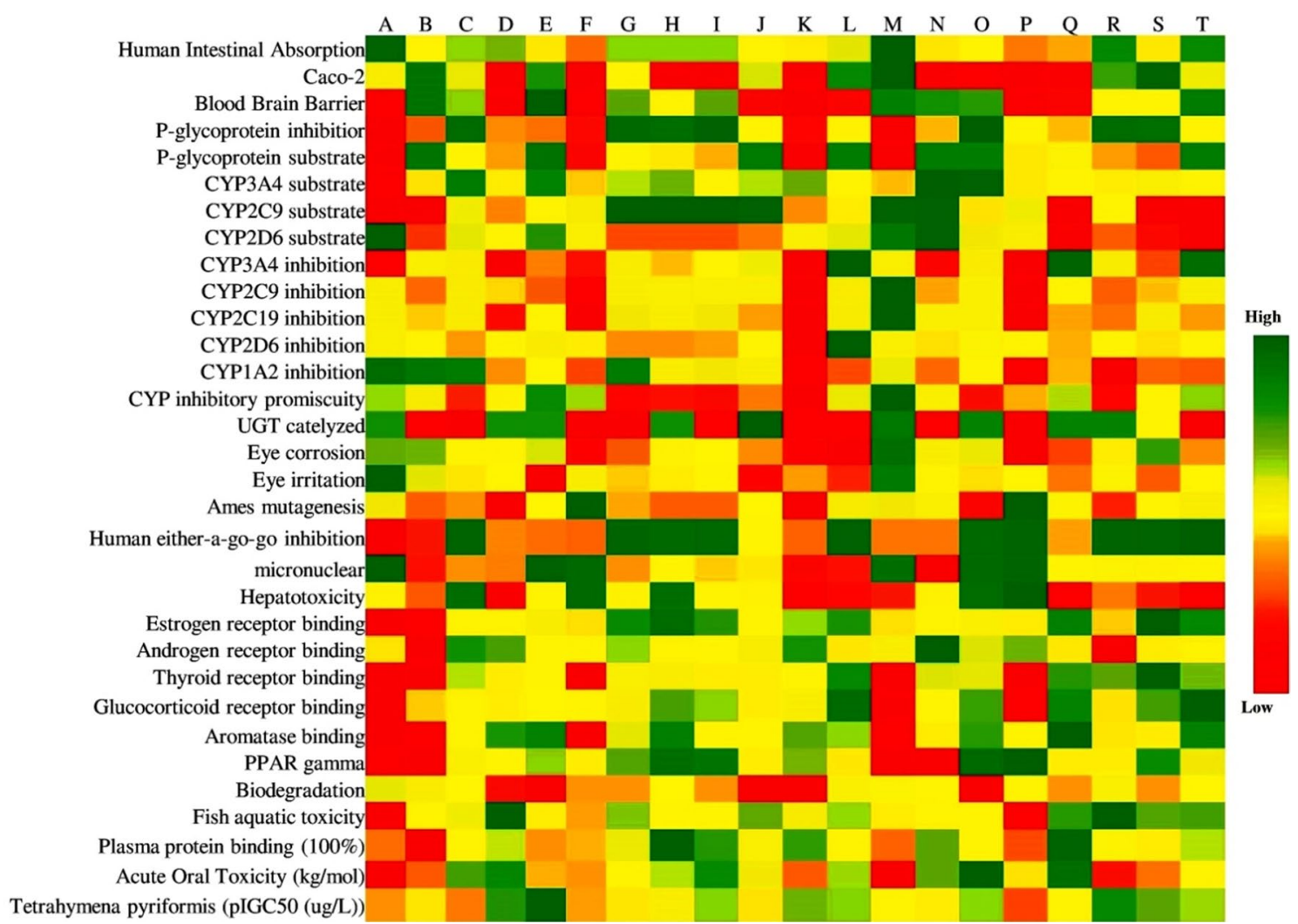

Fig. 4 Absorption, distribution, metabolism, excretion, and toxicity profile of phytoconstituents. a (S)-3,7-dihydroxychroman-4-one, b 1-O-acetyl-4R,6S-britannilactone, c caesalpinin F, d isoceanothic acid, e jerantinine F, $\mathbf{f}$ mangiferin, $\mathbf{g}$ norcaesalpinin A, $\mathbf{h}$ Norcae-

\section{Results and discussion}

\section{Identification of hits as the JAK-STAT regulators}

Twenty-five different medicinal plants were screened and seventeen possessing anti-viral activity (Abutilon indicum, Crescentia alata, Caesalpinia bonduc, Datura metel, Durio zibethinus, Evolvulus alsinoides, Garcinia mangostana, Indigofera tinctoria, Jatropha curcus, Leucas aspera, Orobanche corymbosa, Ricinus communis, Trichodesma indicum, Vitex trifolia, Wedelia Chinensis, Woodfordia fruticosa, and Wrightia tinctoria) were chosen for further study. A total of 174 multiple phytoconstituents were salpinin $\mathrm{B}, \mathbf{i}$ norcaesalpinin $\mathrm{D}, \mathbf{j}$ norcaesalpinin $\mathrm{E}, \mathbf{k}$ platanic acid, $\mathbf{l}$ rotundifuran, $\mathbf{m}$ salicifoliol, $\mathbf{n}$ stigmastane- $3 \beta, 5 \alpha, 6 \beta$-triol, $\mathbf{o}$ taxine $\mathrm{B}$, $\mathbf{p}$ vicenin-3, $\mathbf{q}$ viteagnusin I, $\mathbf{r}$ vitetrifolin $\mathrm{D}, \mathbf{s}$ Vitex norditerpenoid 2, and $\mathbf{t}$ vitexilactone

retrieved from the ChEBI database. Among them, 96 bioactives were identified to modulate the proteins involved in the JAK-STAT pathway. Likewise, 174 molecules were identified to regulate 807 genes; among them, 15 were from the JAK-STAT signaling pathway. Similarly, network analysis identified $\beta$-maaliene as a hit molecule to regulate the highest number of genes, and TRAF5 was a majorly targeted protein (Fig. 2). Similarly, gene ontology analysis of modulated proteins in the JAK-STAT pathway (Fig. 3) reflects the highest gene regulation in the cellular components was from cytoplasm and regulation of biological process and response to stimulus were the major biological processes. 
Table 3 Binding energy and mode of interactions of phytoconstituents with TNF receptor-associated factor 5

\begin{tabular}{|c|c|c|c|}
\hline Ligand & $\begin{array}{l}\text { Binding energy } \\
\text { (kcal/mol) }\end{array}$ & $\begin{array}{l}\text { Number of } \\
\text { hydrogen bonds }\end{array}$ & Hydrogen bond residues \\
\hline $\begin{array}{l}\text { (S)-3,7- } \\
\text { dihydroxychroman-4-one }\end{array}$ & -5.1 & 0 & - \\
\hline $\begin{array}{l}\text { 1-O-acetyl-4R,6S- } \\
\text { britannilactone }\end{array}$ & -5.0 & 3 & Gln431, Ser430, Phe429 \\
\hline 3'-deoxyepisappanol & -6.5 & 3 & Tyr402, Tyr434, Arg393 \\
\hline 3'-deoxysappanol & -5.9 & 2 & Gln431, Gly399 \\
\hline Norcaesalpinin A & -6.6 & 3 & Lys416, Gln431 \\
\hline Norcaesalpinin B & -6.3 & 3 & Ser505, Gly520, Cys521 \\
\hline Vitex norditerpenoid 1 & -6.2 & 1 & Arg441 \\
\hline Vitex norditerpenoid 2 & -6.5 & 1 & Cys443 \\
\hline Brazilein & -6.5 & 1 & Asn535 \\
\hline Brazilin & -6.6 & 1 & Glu531 \\
\hline Caesalpinin C & -6.2 & 2 & Arg418, Lys414 \\
\hline Caesalpinin D & -7.7 & 4 & Gln431, Thr411 \\
\hline Caesalpinin F & -6.1 & 4 & Ser505, Ser507, Ser519 \\
\hline Daturadiol & -8.4 & 0 & - \\
\hline$\delta$-elemene & -5.3 & 0 & - \\
\hline Isoceanothic Acid & -7.2 & 2 & Arg441, Gln431 \\
\hline Jerantinine $\mathrm{F}$ & -6.6 & 1 & Lys416 \\
\hline Mangiferin & -7.3 & 3 & Trp408, Gln431, Gly399 \\
\hline Norcaesalpinin D & -5.4 & 1 & Lys509 \\
\hline Norcaesalpinin E & -6.1 & 1 & Asp541 \\
\hline Platanic acid & -7.5 & 2 & Thr411, Lys416 \\
\hline Rotundifuran & -5.7 & 2 & Trp408, Lys395 \\
\hline Salicifoliol & -5.8 & 2 & Trp408, Gly399 \\
\hline Sandaracopimaric Acid & -7.2 & 1 & Asp540 \\
\hline Sebacic Acid & -4.1 & 2 & Glu531, Lys414 \\
\hline Sesaminol & -7.6 & 0 & - \\
\hline Taxine B & -6.4 & 3 & Gln431, Thr411, Trp408 \\
\hline Vicenin-3 & -6.6 & 9 & $\begin{array}{l}\text { Lys500, Asp502, Ser505, Ser506, Ser507, Gly520, } \\
\text { Ser519 }\end{array}$ \\
\hline Viteagnusin I & -6.7 & 1 & Lys417 \\
\hline Vitetrifolin D & -5.6 & 0 & - \\
\hline Vitexilactone & -6.5 & 1 & Glu531 \\
\hline$(+)$-garcinia acid & -5.1 & 5 & Val421, Asn449, Gly450 \\
\hline (-)- $\alpha$-gurjunene & -5.5 & 0 & - \\
\hline$\beta$-maaliene & -6.6 & 0 & - \\
\hline Gibberellin A45 & -6.9 & 1 & Ser432 \\
\hline Gibberellin A63 & -7.5 & 3 & Thr411, Lys409 \\
\hline $\begin{array}{ll}\begin{array}{l}\text { Sesaminol } \\
\text { gentiobioside }\end{array} & 2-\mathrm{O}-\beta-\mathrm{D}- \\
\end{array}$ & -8.6 & 5 & Gln431, Phe429, Trp408 \\
\hline $\begin{array}{llll}\begin{array}{l}\text { Sesaminol } \\
\text { glucoside }\end{array} & 2-\mathrm{O}- & \beta & -\mathrm{D}- \\
\end{array}$ & -7.8 & 8 & Lys416, Lys409, Trp408, Phe429, Lys395 \\
\hline 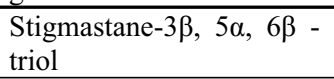 & -6.4 & 2 & $\mathrm{G} \ln 431$ \\
\hline
\end{tabular}




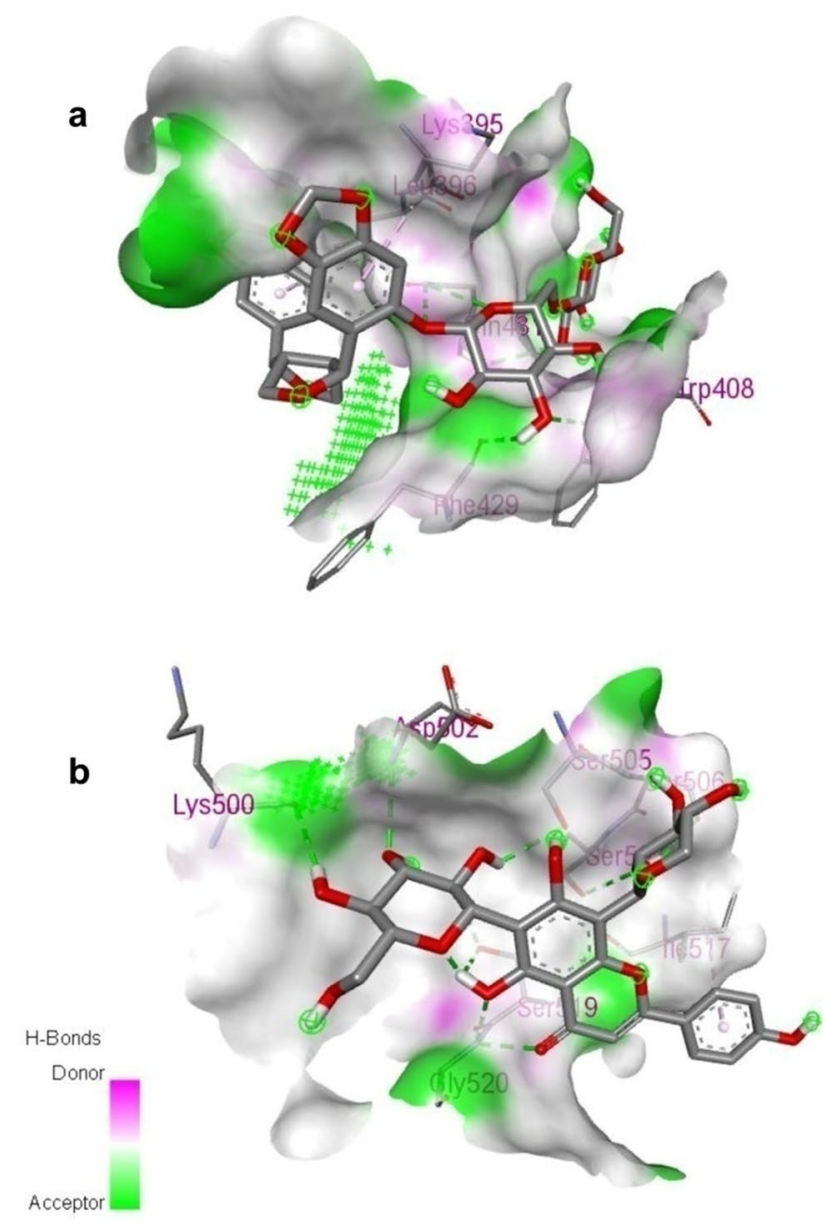

Fig. 5 Interaction of a sesaminol 2-O- $\beta$-D-gentiobioside and $\mathbf{b}$ vicenin-3 with TNF receptor-associated factor 5

\section{Enrichment analysis of JAK-STAT modulated proteins}

Enrichment analysis of proteins identified multiple pathways such as JAK-STAT signaling pathway, viral carcinogenesis, chronic myeloid leukemia, ErbB signaling pathway, apoptosis, Hepatitis B, Necroptosis, HTLV-I infection, NF-kappa B signaling pathway, Th17 cell differentiation, autophagyanimal, mTOR signaling pathway, chemokine signaling pathway, and Ras signaling pathway involved in the regulation of viral infections (Table 1).

\section{Druglikeness and ADMET profile of lead hits}

Vitexilactone, among 39 different phytoconstituents targeting TRAF5, was predicted for the highest druglikeness score, i.e., 0.88. Among them, 18 compounds possessed a non-druglikeness character based on the rule of five. The druglikeness score of each phytoconstituent targeting TRAF5 is summarized in Table 2. Similarly, the ADMET profile of each phytoconstituent is depicted in Fig. 4 as a heat map.

\section{In silico molecular docking}

Sesaminol 2-O- $\beta$-D-gentiobioside, among 39 different phytoconstituents targeting TRAF5, was predicted to have the highest binding affinity (binding energy $-8.6 \mathrm{kcal} / \mathrm{mol}$ ) via 5 hydrogen bond interactions with Gln431, Phe429, and Trp408 amino acids. However, vicenin-3 was predicted to possess the highest number of hydrogen bond interactions, i.e., 9 with Lys500, Asp502, Ser505, Ser506, Ser507, Gly520, and Ser519 amino acids; though scored comparatively lower binding affinity (binding energy $-6.6 \mathrm{kcal} / \mathrm{mol}$ ) than sesaminol 2-O- $\beta$-D-gentiobioside (Table 3 ). The interaction of sesaminol 2-O- $\beta$-D-gentiobioside and vicenin-3 is represented in Fig. 5.

Likewise, sesaminol 2-O- $\beta$-D-glucoside was predicted to possess the highest binding affinity (binding energy $-9.2 \mathrm{kcal} / \mathrm{mol}$ ) with $3 \mathrm{CL}^{\text {pro }}$ via 2 hydrogen bond interactions with Glu166, and Thr190. Similarly, vicenin-3 was predicted to have a binding affinity (binding energy $-8.2 \mathrm{kcal} / \mathrm{mol}$ ) with $3 \mathrm{CL}^{\text {pro }}$ via 5 hydrogen interactions with Gly143, Ser144, and Glu166 (Table 4). The interaction of sesaminol 2-O- $\beta$-D-glucoside and vicenin-3 is represented in Fig. 6.

Sesaminol 2-O- $\beta$-D-gentiobioside was predicted to possess binding affinity (binding energy $-8.5 \mathrm{kcal} / \mathrm{mol}$ ) with $\mathrm{PL}^{\text {pro }}$ via 4 hydrogen bond interactions with Thr75 and Asp77. However, taxine B was predicted to have the highest hydrogen bond interactions, i.e., 6 with Thr171, Arg167, Glu204, Met207, and Gln233 amino acids though it scored comparatively lower binding affinity (binding energy -6.9 kcal/mol) with PL ${ }^{\text {pro }}$ (Table 5); the interaction is represented in Fig. 7.

In addition, sesaminol 2-O- $\beta$-D-gentiobioside was predicted to have the highest binding affinity (binding 
Table 4 Binding energy and mode of interaction of phytoconstituents with $3 \mathrm{CL}^{\text {pro }}$

\begin{tabular}{|c|c|c|c|}
\hline Ligand & $\begin{array}{l}\text { Binding energy } \\
\text { (kcal/mol) }\end{array}$ & $\begin{array}{l}\text { Number of } \\
\text { hydrogen bonds }\end{array}$ & Hydrogen bond residues \\
\hline$(+)$-garcinia acid & -5.6 & 5 & Gln110, Asn151, Thr111 \\
\hline (-)- $\alpha$-gurjunene & -6.4 & 0 & - \\
\hline $\begin{array}{l}\text { (S)-3 7-dihydroxychroman-4- } \\
\text { one }\end{array}$ & -5.8 & 4 & $\begin{array}{lll}\text { Gln110, } & \text { Thr111, } & \text { Asp153, } \\
\text { Ser158 }\end{array}$ \\
\hline \begin{tabular}{ll|}
$1-\mathrm{O}-$ acetyl-4R, & $6 \mathrm{~S}-$ \\
britannilactone & \\
\end{tabular} & -5.8 & 5 & $\begin{array}{l}\text { Asn277, Gly278, } \\
\text { Tyr239, Thr199 }\end{array}$ \\
\hline 3'-deoxyepisappanol & -6.5 & 2 & Asn142, Glu166 \\
\hline 3'-deoxysappanol & -6.7 & 0 & - \\
\hline Norcaesalpinin A & -7.1 & 4 & Thr111, Gln110 \\
\hline Norcaesalpinin B & -7.4 & 2 & Thr292, Gln110 \\
\hline Vitex norditerpenoid 1 & -6.8 & 3 & Gln110, Thr292, Thr111 \\
\hline Vitex norditerpenoid 2 & -7.0 & 5 & $\begin{array}{l}\text { Lys102, Ser158, } \\
\text { Thr292, Gln110 }\end{array}$ \\
\hline$\beta$-maaliene & -6.0 & 0 & - \\
\hline Brazilein & -7.3 & 4 & Gln110, Thr111, Asp295 \\
\hline Brazilin & -7.1 & 2 & Ser158, Thr111 \\
\hline Caesalpinin $\mathrm{C}$ & -6.7 & 3 & Tyr239, Thr199 \\
\hline Caesalpinin D & -7.1 & 3 & Leu287, Tyr239, Tyr237 \\
\hline Caesalpinin $\mathrm{F}$ & -6.7 & 1 & Glu166 \\
\hline Daturadiol & -8.0 & 2 & Asp197, Asn238 \\
\hline$\delta$-elemene & -5.4 & $\overline{0}$ & - \\
\hline Gibberellin A45 & -7.6 & 3 & Gln110, Thr111, Asn151 \\
\hline Gibberellin A63 & -7.4 & 5 & Asn238, Thr199, Asp289 \\
\hline Isoceanothic acid & -7.7 & 2 & Glu166, His164 \\
\hline Jerantinine $\mathrm{F}$ & -7.5 & 0 & - \\
\hline Mangiferin & -8.5 & 5 & Thr190, Ser144, His41, Asn142 \\
\hline Norcaesalpinin D & -6.7 & 3 & Leu287, Arg131, Thr199 \\
\hline Norcaesalpinin E & -6.9 & 5 & $\begin{array}{l}\text { Gly195, Asp197, } \\
\text { Lys137, Thr135 }\end{array}$ \\
\hline Platanic acid & -8.3 & 2 & Leu271, Thr199 \\
\hline Rotundifuran & -6.6 & 2 & Asn151, Gln110 \\
\hline Salicifoliol & -6.5 & 3 & Gly143, Ser144, Cys145 \\
\hline Sandaracopimaric acid & -6.5 & 0 & - \\
\hline Sebacic acid & -4.7 & 2 & Asn151, Thr111 \\
\hline $\begin{array}{ll}\text { Sesaminol } & 2-\mathrm{O}-\beta-\mathrm{D}- \\
\text { gentiobioside } & \\
\end{array}$ & -8.7 & 2 & Glu166, Thr190 \\
\hline Sesaminol 2-O- $\beta$-D-glucoside & -9.2 & 2 & Glu166, Thr190 \\
\hline Sesaminol & -7.9 & 4 & Lys137, Arg131, Tyr239 \\
\hline Stigmastane-3 $3,5 \alpha, 6 \beta$-triol & -6.5 & 3 & Leu287, Tyr239 \\
\hline Taxine B & -7.9 & 3 & Phe294, Gln110 \\
\hline Vicenin-3 & -8.2 & 5 & Gly143, Ser144, Glu166 \\
\hline Viteagnusin I & -6.7 & 4 & $\begin{array}{l}\text { Thr199, Lys137, } \\
\text { Glu288 }\end{array}$ \\
\hline Vitetrifolin D & -6.2 & 4 & Arg131, Thr199 \\
\hline Vitexilactone & -6.9 & 1 & Gln110 \\
\hline
\end{tabular}




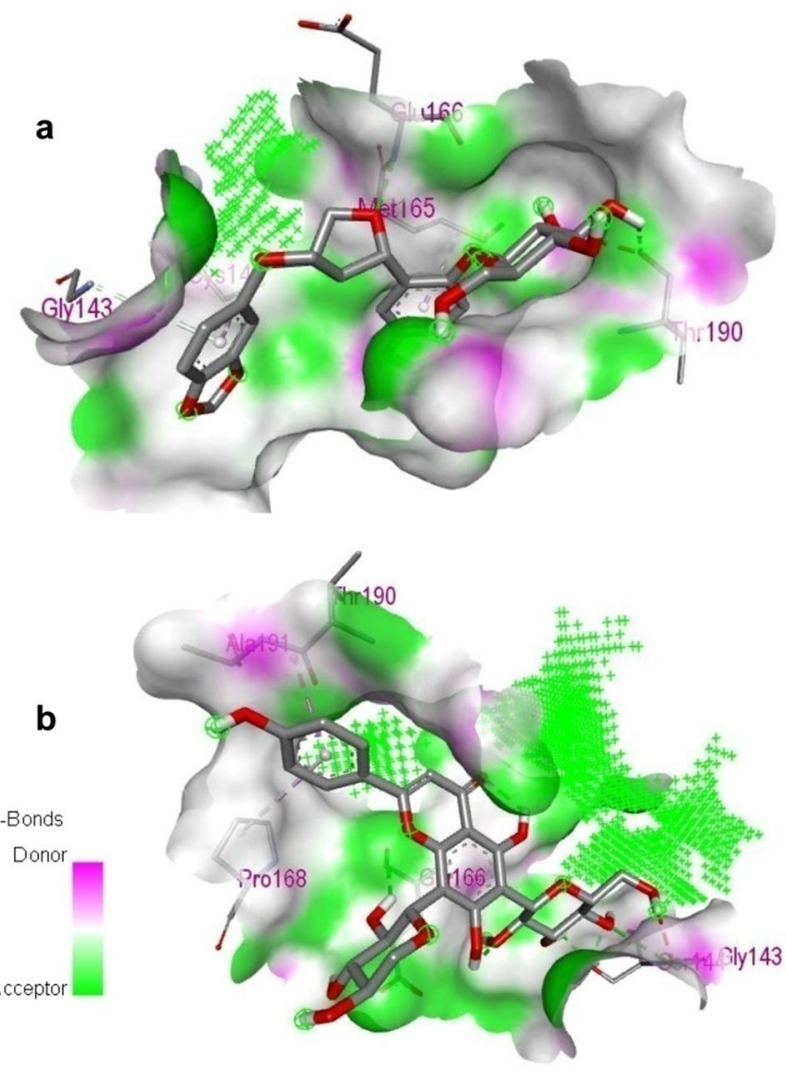

Fig. 6 Interaction of a sesaminol 2-O- $\beta$-D-glucoside and $\mathbf{b}$ vicenin-3 with $3 \mathrm{CL}^{\text {pro }}$

energy $-9.7 \mathrm{kcal} / \mathrm{mol}$ ) with spike protein via 8 hydrogen bond interactions with Thr47, Leu48, Gln825, Ala801, Ala803, Phe805, Lys807, and Asp811 (Table 6); the interaction is represented in Fig. 8.

\section{Phylogeny comparison of $3 \mathrm{CL}^{\text {pro }}, \mathrm{PL}^{\text {pro }}$, and spike protein}

The protein blast identified 3 different proteins, i.e., 3C-like proteinase of porcine transmissible gastroenteritis coronavirus strain Purdue, replicase of transmissible gastroenteritis virus, and $\mathrm{M}^{\text {pro }}$ Transmissible gastroenteritis virus; based on query cover (100\%), E-value (0), and percentage identity $(100 \%)$, these proteins were found to be similar with $3 \mathrm{CL}^{\text {pro }}$. The alignments were also matched with other proteins like Pedv 3c-like protease of diarrhea virus, replicative polyprotein $1 \mathrm{ab}$ of murine hepatitis virus strain A59, and purine nucleoside phosphorylase of Toxoplasma gondii. However, maximum matching was with multiple strains of the coronavirus from different organisms. Similarly, the sequence of $\mathrm{PL}^{\text {pro }}$ was similar to previously reported papain-like protease from coronavirus in England and Jordan. Furthermore, $\mathrm{PL}^{\text {pro }}$ sequence also matched with papain-like protease from other viral strains (Murine hepatitis virus strain A59) by 29.45\%, replicase polyprotein 1ab (Murine hepatitis virus strain A59) by $29.13 \%$, replicase polyprotein $1 \mathrm{ab}$ (Avian infectious bronchitis virus; strain Beaudette) by $27.11 \%$, and nonstructural protein 3 (Avian infectious bronchitis virus; strain Beaudette) by $26.76 \%$. Likewise, spike proteins from other viruses like Murine hepatitis virus strain A59, feline infectious peritonitis virus, infectious bronchitis virus, and porcine epidemic diarrhea virus CV777 were similar to coronavirus. Similarly, $47.06 \%$ of spike protein amino acid sequence matched with Hepcidin; however, this match's E-value was 5. The dendrogram (Fig. 9) represents the hierarchical clustering relationship of $3 \mathrm{CL}^{\text {pro }}, \mathrm{PL}^{\text {pro }}$, and spike protein with respective proteins.

The present study attempted to identify the potential lead hits of JAK-STAT signaling pathway regulators from antiviral Indian traditional medicinal plants and identify the probable homologous proteins of COVID-19 3CL ${ }^{\text {pro }}$, $\mathrm{PL}^{\text {pro }}$, and spike protein concerning an available database. Furthermore, the study also predicted the binding affinity of a lead hit as JAK-STAT regulator with $3 \mathrm{CL}^{\text {pro }}$, $\mathrm{PL}^{\text {pro }}$, and spike protein using in silico molecular docking.

COVID-19 is reported to impair pulmonary gas exchange, primarily in the malfunctioning of the maladjusted immune system. Furthermore, to eliminate the coronavirus infection, the subject's immune system plays an important role ( $\mathrm{Li}$ et al. 2020). KEGG database also records the JAK-STAT pathway for multiple immunological disorders, including JAK-STAT signaling for viruses (pathway entry: hsa04630). Hence, identifying lead hits to modulate the JAK-STAT pathway proteins from the medicinal plants can play an essential role in regulating an immune system as a home remedy and may help as a preventive approach to deal with corona infection. Furthermore, we were interested in knowing if $3 \mathrm{CL}^{\text {pro }}, \mathrm{PL}^{\text {pro }}$, and spike protein share their amino acid sequence with any other predeposited proteins in the RCSB databank.

Interestingly, we identified $3 \mathrm{CL}^{\text {pro }}$ to share its amino acid sequences with other microbial infections like PEDV main protease from Porcine epidemic diarrhea virus CV777. Furthermore, $\mathrm{PL}^{\text {pro }}$ also shared its amino acid sequence with 
Table 5 Binding energy and mode of interaction of phytoconstituents with PL ${ }^{\text {pro }}$

\begin{tabular}{|c|c|c|c|}
\hline Ligand & $\begin{array}{l}\text { Binding energy } \\
\text { (kcal/mol) }\end{array}$ & $\begin{array}{l}\text { Number of hydrogen } \\
\text { bonds }\end{array}$ & Hydrogen bond residues \\
\hline$(+)$-garcinia acid & -5.5 & 44 & Gly272, Tyr265, Gly164 \\
\hline (-)- $\alpha$-gurjunene & -6.0 & 0 & - \\
\hline (S)-3, 7-dihydroxychroman-4-one & -5.7 & 0 & - \\
\hline 1-O-acetyl-4R, 6S-britannilactone & -7.0 & 2 & Tyr269, Gly272 \\
\hline 3'-deoxyepisappanol & -6.6 & 1 & Tyr269 \\
\hline 3'-deoxysappanol & -6.8 & 1 & Gly164 \\
\hline Norcaesalpinin A & -6.7 & 5 & Asn178, Ser181, Ala182 \\
\hline Norcaesalpinin B & -7.3 & 5 & Tyr252, Ser213, Asp215, Tyr214 \\
\hline Vitex norditerpenoid 1 & -6.2 & 1 & Tyr306 \\
\hline Vitex norditerpenoid 2 & -6.0 & 0 & - \\
\hline$\beta$-maaliene & -5.8 & 0 & - \\
\hline Brazilein & -8.0 & 0 & - \\
\hline Brazilin & -7.5 & 4 & Thr55, Tyr36, Gly39, Arg139 \\
\hline Caesalpinin $\mathrm{C}$ & -7.1 & 2 & Tyr265, Tyr269 \\
\hline Caesalpinin D & -7.9 & 2 & Tyr274, Tyr265 \\
\hline Caesalpinin F & -6.4 & 0 & - \\
\hline Daturadiol & -7.8 & 2 & Gln233, Met207 \\
\hline$\delta$-elemene & -5.3 & 0 & - \\
\hline Gibberellin A45 & -6.9 & 3 & Tyr265, Asp165 \\
\hline Gibberellin A63 & -7.3 & 0 & - \\
\hline Isoceanothic Acid & -7.0 & 4 & Ser310, Glu308, Thr309, Asp215 \\
\hline Jerantinine $\mathrm{F}$ & -6.6 & 1 & Phe259 \\
\hline Mangiferin & -7.3 & 1 & Ser181 \\
\hline Norcaesalpinin D & -6.1 & 3 & Arg167, Gln233, Tyr208 \\
\hline Norcaesalpinin E & -7.3 & 3 & Tyr265, Tyr274 \\
\hline Platonic acid & -7.1 & 2 & Gln233 \\
\hline Rotundifuran & -6.9 & 4 & Lys158, Tyr269, Tyr265, Thr302 \\
\hline Salicifoliol & -7.1 & 2 & Thr302, Tyr274 \\
\hline Sandaracopimaric Acid & -6.7 & 1 & Tyr269 \\
\hline Sebacic acid & -5.4 & 1 & Thr302 \\
\hline Sesaminol 2-O- $\beta$-D-gentiobioside & -8.5 & 4 & Thr75, Asp77 \\
\hline Sesaminol 2-O- $\beta$-D-glucoside & -7.5 & 4 & Lys218, Phe259, Lys280, Ala279 \\
\hline Sesaminol & -8.2 & 2 & Tyr265, Tyr269 \\
\hline Stigmastane- $3 \beta, 5 \alpha, 6 \beta$-triol & -6.2 & 4 & Gln233, Tyr208, Met209 \\
\hline Taxine B & -6.9 & 6 & Thr171, Arg167, Glu204, Met207, Gln233 \\
\hline Vicenin-3 & -6.9 & 2 & Ser181, Ser241 \\
\hline Viteagnusin I & -7.4 & 4 & Tyr265, Lys158, Tyr274, Thr302 \\
\hline Vitetrifolin D & -6.4 & 2 & Arg167, Tyr265 \\
\hline Vitexilactone & -7.3 & 3 & Lys158, Thr302, Tyr265 \\
\hline
\end{tabular}


a

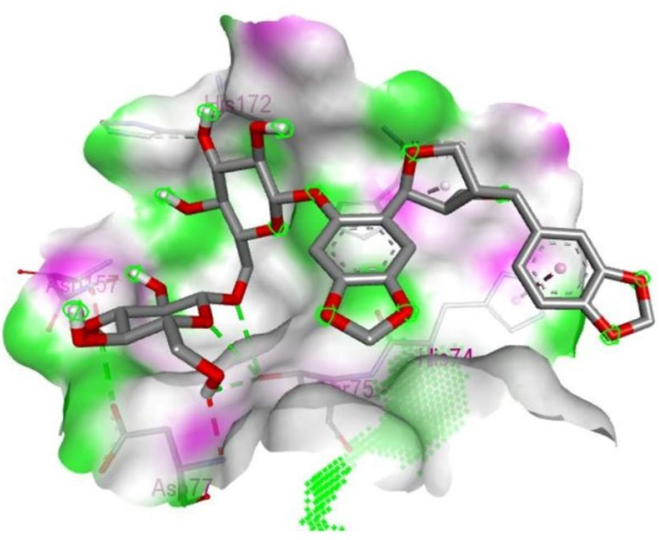

b

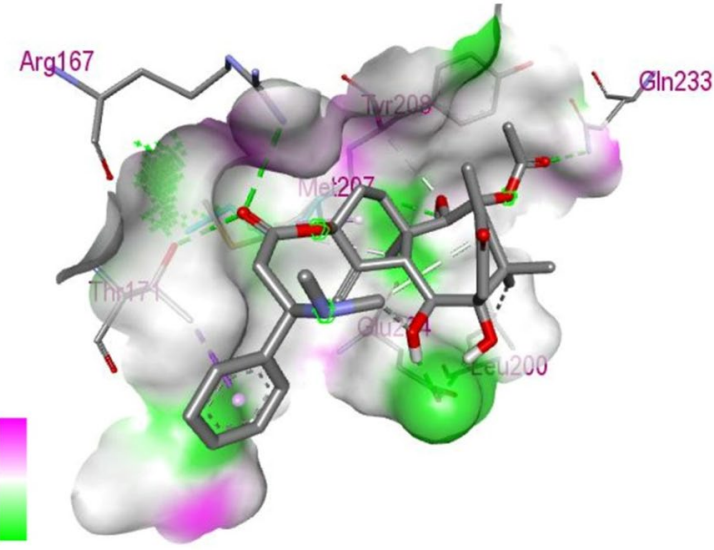

Fig. 7 Interaction of a sesaminol 2-O- $\beta$-D-gentiobioside and $\mathbf{b}$ taxine B with PL ${ }^{\text {pro }}$

replicase polyprotein $1 \mathrm{ab}$ of Murine hepatitis virus strain A59. Likewise, spike protein possessed similar amino acid alignments with spike glycoprotein of Murine hepatitis virus strain A59. This observation suggests that analogues of protease inhibitors from procaine epidemic diarrhea could be chosen as the investigative molecule against $3 \mathrm{CL}^{\text {pro }}$. Similarly, analogues of replicase polyprotein 1ab and spike glycoprotein of Murine hepatitis virus strain A59 could act over the $\mathrm{PL}^{\text {pro }}$ and spike protein, respectively.

Enrichment analysis of modulated proteins from JAKSTAT pathways identified the multiple pathways which may contribute to maintain an immune system like apoptosis, necroptosis, Th1, and Th2 cell differentiation, NF-kappa B signaling pathway, Th17 cell differentiation, and chemokine signaling pathway. Coronavirus replication is linked with the membrane of the endoplasmic reticulum and is reported to increase stress over it; leads to apoptosis via unfolded protein response (Fung and Liu 2014). Likewise, the corona virus-induced necrotic cell death may occur due to multiple mechanisms like Rip3-induced oligomerization, mixed lineage kinase domain-like protein dispensed cell death, necroptotic elements-induced human lung cell damage, lysosomeinduced damage, and activation of multiple inflammasomes (Yue 2018). Hence, modulation of these pathways' may contribute to the immune system's homeostatic regulation and reduce cell apoptosis and necrosis. Other pathways involving T-helper cells, cytokine, and chemokine signallers are also closely associated in enhancing the immune system that may contribute towards up-/down- regulation of the immune system during corona infection (Padovan 2017; Simon 2011; Jang et al. 2005).

The network pharmacology screening of multiple phytoconstituents from folk medicines has identified the $\beta$-maaliene to regulate the highest number of proteins. The probable checkpoints affected by $\beta$-maaliene in the JAKSTAT pathway are presented in Fig. 10. Although, based on the literature search, we did not find any reported antiviral activity of $\beta$-maaliene, our prediction of the biological spectrum via Prediction of Activity Spectra for Substances (PASS) ONLINE (Lagunin et al. 2000) identified it to possess an anti-viral effect against influenza, adenovirus, Cytomegalovirus, Herpes, Picornavirus, and Hepatitis C. Furthermore, the compound was also envisioned as viral entry inhibitor. So, apart from modulating the JAK-STAT pathway proteins, $\beta$-maaliene may also act over the spike protein of coronavirus and inhibit its entry into the cell. Furthermore, these calculations suggest that analogs of $\beta$-maaliene could be the choice of investigative molecules as a modulator of the JAK-STAT pathway and inhibitor of virus entry into host cells.

We identified TRAF5 protein that may be modulated by the highest number of phytoconstituents during network pharmacology-evident target identification. A previous report suggested that the requirement of TRAF5 optimizes the $\mathrm{T}$ cell expansion in response to infection (Kraus et al. 2008). Hence, we attempted to identify the lead hit agent as the prime modulator of TRAF5 from the list of phytoconstituents. Based on the binding energy and number of 
Table 6 Binding energy and mode of interaction of phytoconstituents with spike protein

\begin{tabular}{|c|c|c|c|}
\hline Ligand & $\begin{array}{l}\text { Binding } \\
\text { energy } \\
\text { (kcal/mol) }\end{array}$ & $\begin{array}{l}\text { Number } \\
\text { hydrogen } \\
\text { bonds }\end{array}$ & Hydrogen bond residues \\
\hline$(+)$-garcinia acid & -5.7 & $\frac{5}{5}$ & Tyr66, Thr94, Asn185, Ala255 \\
\hline (-)- $\alpha$-gurjunene & -6.6 & 0 & - \\
\hline (S)-3,7-dihydroxychroman-4-one & -6.2 & 2 & Ala608, Tyr588 \\
\hline 1-O-acetyl-4R,6S-britannilactone & -6.0 & 2 & Thr525, Arg314 \\
\hline 3'-deoxyepisappanol & -7.1 & 1 & Asp595 \\
\hline 3'-deoxysappanol & -7.0 & 2 & Ile600, Ile611 \\
\hline Norcaesalpinin A & -6.7 & 3 & Arg77, Asp137, Tyr136 \\
\hline Norcaesalpinin B & -7.0 & 1 & Ala259 \\
\hline Vitex norditerpenoid 1 & -6.5 & 0 & - \\
\hline Vitex norditerpenoid 2 & -6.7 & 3 & Thr94, Tyr66, Ala255 \\
\hline$\beta$-maaliene & -6.3 & 0 & - \\
\hline Brazilein & -7.0 & 2 & Ile881, His1020 \\
\hline Brazilin & -6.8 & 4 & Gly716, Asp717, Leu938, Arg972 \\
\hline Caesalpinin C & -6.7 & 2 & Tyr136 \\
\hline Caesalpinin D & -7.4 & 4 & Leu493, Asn495, Ser490, Arg350 \\
\hline Caesalpinin F & -6.6 & 4 & Tyr136, Asp137, Tyr139 \\
\hline Daturadiol & -8.2 & 1 & Asp820 \\
\hline$\delta$-elemene & -5.3 & 0 & - \\
\hline Gibberellin A45 & -6.9 & 1 & Lys807 \\
\hline Gibberellin A63 & -7.2 & 0 & - \\
\hline Isoceanothic acid & -7.7 & 4 & Thr799, Gln304, Ser300, Ser302 \\
\hline Jerantinine $\mathrm{F}$ & -7.1 & 2 & Ala287, Leu288 \\
\hline Mangiferin & -8.0 & 3 & Ala801, Phe805, Asp46 \\
\hline Norcaesalpinin D & -7.3 & 1 & Gln 825 \\
\hline Norcaesalpinin E & -6.8 & 2 & Gln825, Asp811 \\
\hline Platanic acid & -7.9 & 1 & Arg268 \\
\hline Rotundifuran & -6.2 & 2 & Ile600, Lys266 \\
\hline Salicifoliol & -6.1 & $\overline{0}$ & - \\
\hline Sandaracopimaric acid & -8.3 & 0 & - \\
\hline Sebacic acid & -4.1 & 3 & Arg77, Tyr139, Ala156 \\
\hline Sesaminol 2-O- $\beta$-D-gentiobioside & -9.7 & 8 & $\begin{array}{l}\text { Thr47, Leu48, Gln825, Ala801, Ala803, } \\
\text { Phe805, Lys807, Asp811 }\end{array}$ \\
\hline Sesaminol 2-O- $\beta$-D-glucoside & -7.9 & 3 & Lys705, Thr831, Ile816 \\
\hline Sesaminol & -7.7 & 3 & Ser460, Trp348, Asn417 \\
\hline Stigmastane-3 $3,5 \alpha, 6 \beta$-triol & $\begin{array}{ll}-7.8 \\
\end{array}$ & 1 & Tyr59 \\
\hline Taxine B & -8.1 & 1 & Thr47 \\
\hline Vicenin-3 & -8.0 & 4 & Tyr59, Ile600, Ala287, Thr599 \\
\hline Viteagnusin I & $\begin{array}{l}-7.4 \\
\end{array}$ & 2 & Thr47, Leu48 \\
\hline Vitetrifolin D & -6.2 & 5 & Asp46, Asp811, Gln825 \\
\hline Vitexilactone & -6.9 & 4 & Leu48, Thr47, Gly814, Lys807 \\
\hline
\end{tabular}




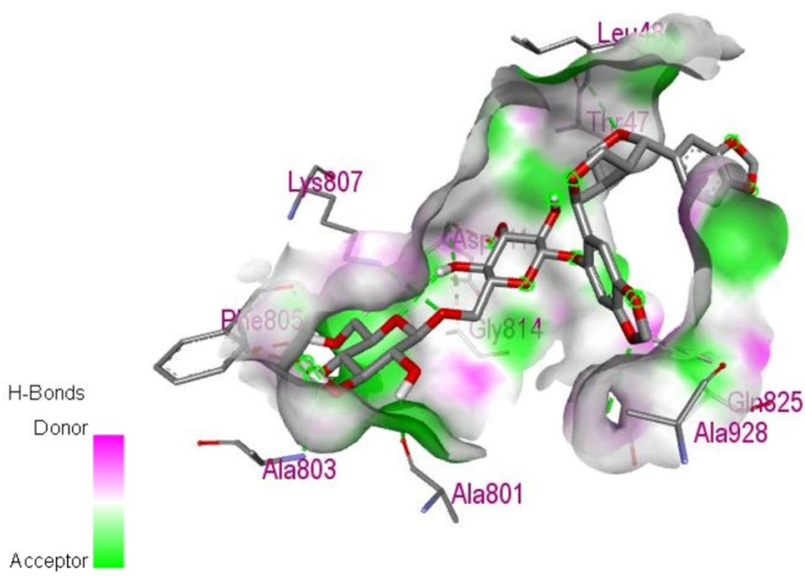

Fig. 8 Interaction of sesaminol 2-O- $\beta$-D-gentiobioside with spike protein

hydrogen bond interactions we identified sesaminol 2-O- $\beta$ D-gentiobioside and vicenin-3 to possess the best interaction with TRAF5. Furthermore, TRAF5 modulators were also docked with $3 \mathrm{CL}^{\mathrm{pro}}, \mathrm{PL}^{\mathrm{pro}}$, and spike protein; and found that sesaminol 2-O- $\beta$-D-gentiobioside, taxine $\mathrm{B}$, vicenin-3, and sesaminol 2-O- $\beta$-D-glucoside as lead hits. In addition, PASS (Lagunin et al. 2000) helps to identify the probable anti-viral compounds by querying the SMILES of molecules which predicted plausible anti-viral properties against Influenza (Pa: 0.733), Hepatitis B (Pa: 0.402), and Herpes (Pa: 0.371 ) by sesaminol 2-O- $\beta$-D-gentiobioside (1), Rhinovirus (Pa:0.324) by Taxine B (2), Herpesvirus (Pa: 0.842), Influenza (Pa: 0.540), Hepatitis B virus (Pa: 0.443), Picornavirus (Pa: 0.349), Poxvirus (Pa: 0.237), Hepatitis (Pa: 0.136), and Retrovirus (Pa: 0.133) by vicenin-3 (3) and Influenza (Pa: 0.690), Hepatitis B (Pa: 0.378), Herpes (Pa: 0.396), Rhinovirus (Pa:0.305) by sesaminol 2-O- $\beta$-D-glucoside (4). Docking study also revealed the probable binding affinity of these molecules with $3 \mathrm{CL}^{\mathrm{pro}}, \mathrm{PL}^{\mathrm{pro}}$, and spike protein. These targets also shared the similar amino acid sequence with proteins from other viruses; hence, these molecules may be further screened via their functional group modeling to target coronavirus with the proper assessment of protein domain of target of interest.

Although the present screening focused in identifying the lead hit anti-viral molecules against COVID-19, Indian herbal medicinal plants were screened via network pharmacology and gene enrichment analysis; is a concept via "multi compounds-multi protein" interaction. Furthermore, the present study's outcome is knowledge-based and depends on multiple regression models for particular biological activities. On the other hand, during COVID-19 infection, the dysregulated immune system may play an essential role in spreading the virus in the host system; it could be maintained via the JAK-STAT signaling pathway, the main basic concept of the present study. Likewise, identifying the homologous proteins may also play a crucial role in identifying new drug molecules that kindled us for phylogeny comparison of targets based on the predeposited amino acid sequences of individual proteins.

\section{Conclusion}

The present study identified few lead hits from the traditional Indian medicines reported for their anti-viral property against COVID-19. Further phylogeny comparison also reflected that the coronavirus proteins may share a common domain with other similar microbial proteins. It also suggests that reported inhibitors of such proteins could be implemented in screening the molecules as $3 \mathrm{CL}^{\text {pro }}, \mathrm{PL}^{\text {pro }}$, and spike protein inhibitors. However, the present findings are based on available databases and computer simulations. Hence, further investigations using wet-lab protocols are required to confirm the conclusions accordingly. 

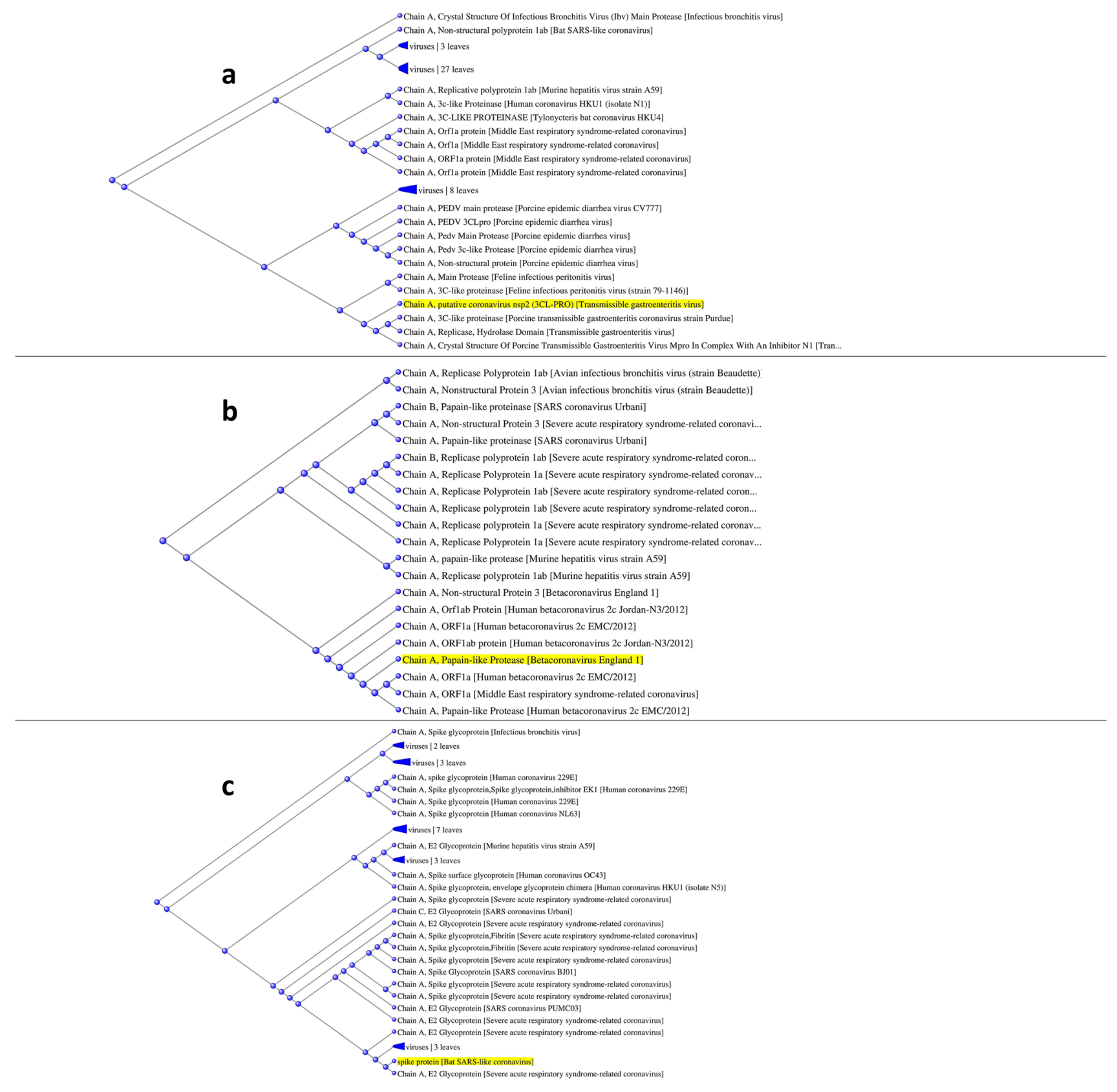

Fig. 9 Hierarchical clustering relationship of $\mathbf{a} 3 \mathrm{CL}^{\text {pro }}, \mathbf{b} \mathrm{PL}^{\text {pro }}$, and $\mathbf{c}$ spike protein with multiple proteins 


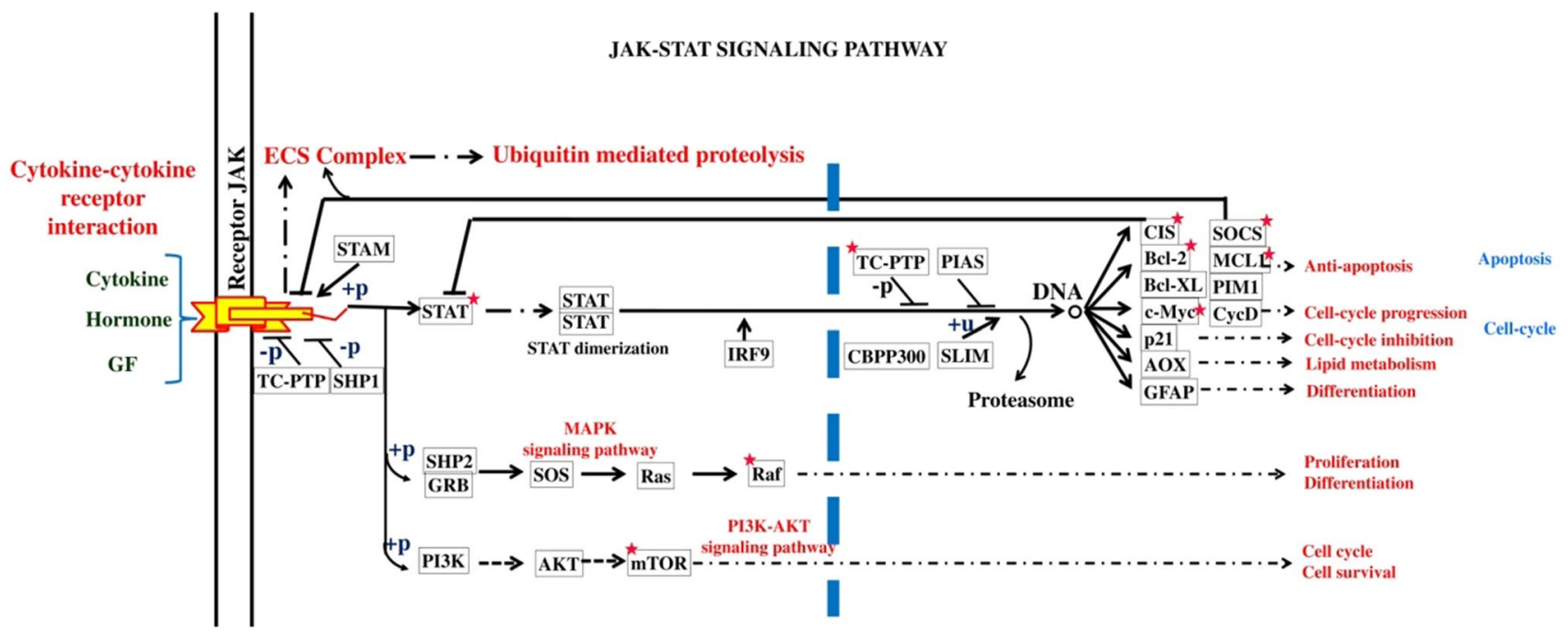

Fig. 10 Probable checkpoints affected by $\beta$-maaliene in JAK-STAT pathway. ${ }^{\star}$ targeted proteins by $\beta$-maaliene

Author contributions Pukar Khanal performed a review of the literature, mined the data, constructed the in-house database, performed the study, and drafted the manuscript. Taaza Duyu assisted in performing the study, drafting, and reviewing the manuscript. BM Patil and Yadu Nandan Dey equally contributed to performing the review of literature, drafting, and reviewing the manuscript. Ismail Pasha, Rohini S. Kavalapure, Sharad Chand, and Shailendra Gurav contributed to the final refinement of the manuscript.

Funding This work has not received any funds from national or international agencies.

Data availability The raw data/results for the present study are available from Pukar Khanal (pukarkhanal58@gmail.com) upon request.

\section{Compliance with ethical standards}

Conflict of interest All the authors of this manuscript have no conflict of interest.

Ethical statement This article does not contain any studies with human participants or animals performed by any of the authors.

\section{References}

Altschul SF, Madden TL, Schäffer AA, Zhang J, Zhang Z, Miller W, Lipman DJ (1997) Gapped BLAST and PSI-BLAST: a new generation of protein database search programs. Nucleic Acids Res 25:3389-3402. https://doi.org/10.1093/nar/25.17.3389

Bhoj VG, Chen ZJ (2009) Ubiquitylation in innate and adaptive immunity. Nature 458:430-437. https://doi.org/10.1038/nature07959

Chikhale RV, Sinha SK, Patil RB, Prasad SK, Shakya A, Gurav NS, Prasad RS, Dhaswadikar SR, Wanjari M (2020a) Gurav SS (2020a) In-silico investigation of phytochemicals from Asparagus racemosus as plausible antiviral agent in COVID-19. J Biomol Struct Dyn 10(1080/07391102):1784289

Chikhale RV, Gurav SS, Patil RB, Sinha SK, Prasad SK, Shakya A, Shrivastava SK, Gurav NS (2020b) Prasad RS (2020b) Sars-cov-2 host entry and replication inhibitors from Indian ginseng: an in-silico approach. J Biomol Struct Dyn 10(1080/07391102):1778539

Chikhale RV, Sinha SK, Wanjari M, Gurav NS, Ayyanar M, Prasad SK, Khanal P, Dey YN, Patil RB, Gurav SS (2020c) Computational assessment of Saikosaponins as adjuvant treatment for covid-19: molecular docking, dynamics, and network pharmacology analysis. Mol Diversity. https://doi.org/10.1007/s11030-021-10183-w

Dassault Systèmes BIOVIA (2019). Dassault Systèmes, San Diego, Discovery studio, 2019

Fung TS, Liu DX (2014) Coronavirus infection, ER stress, apoptosis and innate immunity. Front Microbiol 5:296. https://doi. org/10.3389/fmicb.2014.00296

Halgren TA (1996) Merck molecular force field. I. Basis, form, scope, parameterization, and performance of MMFF94. Mol Microbiol 1996:490-519

Jang MH, Seoh JY, Miyasaka M (2005) Cytokines, chemokines, and their receptors: targets for immunomodulation. Conference report: International Cytokine Society Conference 2005. J Leukoc Biol 80:217-219

Khanal P, Duyu T, Patil BM, Dey YN, Pasha I, Wanjari M, Gurav SS, Maity A (2020a) Network pharmacology of AYUSH recommended immune-boosting medicinal plants against COVID-19. J Ayurveda Integr Med. https://doi.org/10.1016/j.jaim.2020.11.004

Khanal P, Patil BM, Chand J, Naaz Y (2020b) Anthraquinone Derivatives as an Immune booster and their therapeutic option against COVID-19. Nat Prod Bioprospect 10(5):325-335. https://doi. org/10.1007/s13659-020-00260-2

Khanal P, Chikhale RV, Dey YN, Pasha I, Chand S, Gurav NS, Ayyanar M, Patil BM, Gurav SS (2021a) Withanolides from Withania somnifera as an immunity booster and their therapeutic options against COVID-19. J Biomol Struct Dyn. https://doi.org/10.1080/07391 102.2020.1869588

Khanal P, Dey YN, Patil R, Chikhale R, Wanjari MM, Gurav SS, Patil BM, Srivastava B, Gaidhani SN (2021b) Combination of system biology to probe the anti-viral activity of andrographolide and its derivative against COVID-19. RSC Adv. 11:5065-5079

Kraus ZJ, Haring JS, Bishop GA (2008) TNF receptor-associated factor 5 is required for optimal $\mathrm{T}$ cell expansion and survival in response to infection. J Immun 181:7800-7809. https://doi.org/10.4049/ jimmunol.181.11.7800

Kuhn JH, Li W, Choe H, Farzan M (2004) Angiotensin-converting enzyme 2: a functional receptor for SARS coronavirus. Cell

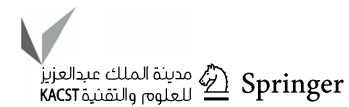


Mol Life Sci 61:2738-2743. https://doi.org/10.1007/s0001 8-004-4242-5

Lagunin A, Stepanchikova A, Filimonov D, Poroikov V (2000) PASS: prediction of activity spectra for biologically active substances. Bioinformatics 16:747-748. https://doi.org/10.1093/bioinforma tics/16.8.747

Lagunin A, Ivanov S, Rudik A, Filimonov D, Poroikov V (2013) DIGEP-Pred: web service for in silico prediction of drug-induced gene expression profiles based on structural formula. Bioinformatics 29:2062-2063. https://doi.org/10.1093/bioinformatics/btt322

Li G, Fan Y, Lai Y, Han T, Li Z, Zhou P, Pan P, Wang W, Hu D, Liu $\mathrm{X}$, Zhang Q, Wu J (2020) Coronavirus infections and immune responses. J Med Virol 92:424-432. https://doi.org/10.1002/ jmv. 25685

Lindner HA, Fotouhi-Ardakani N, Lytvyn V, Lachance P, Sulea T, Ménard R (2005) The papain-like protease from the severe acute respiratory syndrome coronavirus is a deubiquitinating enzyme. $\mathrm{J}$ Virol 79:15199-15208. https://doi.org/10.1128/JVI.79.24.15199 $-15208.2005$

Lipinski CA (2004) Lead- and drug-like compounds: The rule-of-five revolution. Drug Discov Today Technol 1(4):337-341. https://doi. org/10.1016/j.ddtec.2004.11.007

Luo J, Lu S, Yu M, Zhu L, Zhu C, Li C, Fang J, Zhu X, Wang X (2020) The potential involvement of JAK-STAT signaling pathway in the COVID-19 infection assisted by ACE2. Gene. https://doi. org/10.1016/j.gene.2020.145325

Morris GM, Huey R, Lindstrom W, Sanner MF, Belew RK, Goodsell DS, Olson AJ (2009) AutoDock4 and AutoDockTools4: Automated docking with selective receptor flexibility. J Comput Chem 30:2785-2791. https://doi.org/10.1002/jcc.21256

Padovan E (2017) Modulation of CD4+ T Helper Cell Memory Responses in the Human Skin. Int Arch Allergy Immunol 173:121-137. https://doi.org/10.1159/000477728

Patil R, Chikhale R, Khanal P, Gurav N, Ayyanar M, Sinha S, Prasad S, Dey YN, Wanjari M, Gurav SS (2020) Computational and Network Pharmacology Analysis of Bioflavonoids as Possible Natural Antiviral Compounds in COVID-19. Inform Med Unlocked 22:100504. https://doi.org/10.1016/j.imu.2020.100504

Satarker S, Tom AA, Shaji RA, Alosious A, Luvis M, Nampoothiri M (2020) JAK-STAT Pathway Inhibition and their Implications in COVID-19 Therapy. Postgrad Med. https://doi.org/10.1080/00325 481.2020 .1855921

Schwede T, Kopp J, Guex N, Peitsch MC (2003) SWISS-MODEL: An automated protein homology-modeling server. Nucleic Acids Res 31:3381-3385. https://doi.org/10.1093/nar/gkg520
Shannon P, Markiel A, Ozier O, Baliga NS, Wang JT, Ramage D, Amin N, Schwikowski B, Ideker T (2003) Cytoscape: a software environment for integrated models of biomolecular interaction networks. Genome Res 13:2498-2504. https://doi.org/10.1101/ gr.1239303

Simon F (2011) Immunomodulatory cytokines: directing and controlling immune activation. Arthritis Res Ther 13:O14. https://doi. org/10.1186/ar3418

Sinha SK, Prasad SK, Islam MA, Gurav SS, Patil RB, AlFaris NA, Aldayel TS, AlKehayez NM, Wabaidur SM, Shakya A (2020) Identification of bioactive compounds from Glycyrrhiza glabra as possible inhibitor of SARS-CoV-2 spike glycoprotein and non-structural protein-15: a pharmacoinformatics study. J Biomol Struct Dyn. https://doi.org/10.1080/07391102.2020.1779132

Sinha SK, Shakya A, Prasad SK, Singh S, Gurav NS, Prasad RS, Gurav SS (2020) An in-silico evaluation of different Saikosaponins for their potency against SARS-CoV-2 using NSP15 and fusion spike glycoprotein as targets. J Biomol Struct Dyn. https://doi. org/10.1080/07391102.2020.1762741

Szklarczyk D, Gable AL, Lyon D, Junge A, Wyder S, Huerta-Cepas J, Simonovic M, Doncheva NT, Morris JH, Bork P, Jensen LJ, Mering CV (2019) STRING v11: protein-protein association networks with increased coverage, supporting functional discovery in genome-wide experimental datasets. Nucleic Acids Res 47:D607D613. https://doi.org/10.1093/nar/gky1131

Villarino AV, Kanno Y, O'Shea JJ (2017) Mechanisms and consequences of Jak-STAT signaling in the immune system. Nat Immunol 18(4):374-384. https://doi.org/10.1038/ni.3691

WHO (2020) Report of the WHO-China Joint Mission on Coronavirus Disease 2019 (COVID-19). Available at: https://www.who. int/docs/default-source/coronaviruse/who-china-joint-mission-oncovid-19-final-report.pdf Accessed on 27 March 2020

Yang H, Lou C, Sun L, Li J, Cai Y, Wang Z, Li W, Liu G, Tang Y (2019) admetSAR 2.0: web-service for prediction and optimization of chemical ADMET properties. Bioinformatics 35:10671069. https://doi.org/10.1093/bioinformatics/bty707

Yue Y, Nabar NR, Shi CS, Kamenyeva O, Xiao X, Hwang IY, Wang M, Kehrl JH (2018) SARS-Coronavirus Open Reading Frame-3a drives multimodal necrotic cell death. Cell Death Dis 9:904. https ://doi.org/10.1038/s41419-018-0917-y

Zhang DH, Wu KL, Zhang X, Deng SQ, Peng B (2020) In silico screening of Chinese herbal medicines with the potential to directly inhibit 2019 novel coronavirus. J Integr Med 18:152-158. https://doi.org/10.1016/j.joim.2020.02.005 